\title{
One year in an eye casualty clinic
}

\author{
A PAGE CHIAPELLA' AND A RALPH ROSENTHAL 12 \\ From the 'Division of Ophthalmology, Stanford University Medical Center, USA, and the ${ }^{2}$ Department of \\ Ophthalmology, University of Leicester School of Medicine
}

SUMmARY A survey of patients visiting the eye casualty clinic of the Leicester Royal Infirmary was conducted during a one-year period. Demographic and clinical data were collected for 6576 patients. Data were recorded by both medical and clerical personnel during each patient visit. In addition to reporting the main demographic variables in the study, the most common diagnoses and occupations were analysed separately. The main diagnoses fell into two groups: trauma and acute infection/inflammation. The frequency of eye trauma in males was twice that in females. Trauma in adults was strongly influenced by occupation. Common occupations presenting with eye injury were press and machine tool operators, motor vehicle and aircraft mechanics, metal and sheet metal workers, construction and general labourers, electricians, welders, bus/lorry drivers and painter/decorators. Infections were in general distributed evenly throughout the population. The most common infection reported was acute conjunctivitis.

The cost to society of acute eye disease has led to increasing interest in the distribution of these diseases. Particular emphasis has been placed on eye trauma. Several studies have addressed the problem of eye trauma in the community ${ }^{1.5}$ and in children in particular. ${ }^{6-8}$ These studies generally included data which was collected from hospital records and whose focus was on severe injury. Surveys of ocular presentations of small numbers of patients to general emergency departments have also been conducted. ${ }^{911}$ In most reports of eye casualty problems attention is generally directed towards management rather than occurrence of disease. In order to survey the broad range of eye casualty problems that require medical attention we initiated a project to evaluate an eye casualty clinic which is part of a general health care system serving a large community.

The study took place at the Eye Clinic of the Leicester Royal Infirmary (LRI), which has the only ophthalmology service in the Leicestershire Health Authority (LHA) and hence has a unique catchment population of eye disease. Of the approximately 835000 inhabitants served by the Leicestershire Health Authority about $42 \%$ live in and around the city of Leicester. The eye casualty clinic is located within the general eye clinic and is the only eye casualty unit in the LHA.

Correspondence to A Ralph Rosenthal, MD, Department of Ophthalmology, Leicester University School of Medicine, PO Box 65, Leicester LE2 7LX, England.
In this paper we present summary statistics for several demographic and clinical variables of eye casualty patients seen at the LRI during a one-year period. We then looked further at the eye disease observed in the main occupational groups.

\section{Materials and Methods}

Data were obtained for 6987 patients visiting the eye casualty clinic of the LRI between 1 September 1981 and 31 August 1982. A set of variables which encompased both demographic and clinical data was collected at each patient's initial visit to the clinic. Variables included the following: hospital record number, visit date, consultant ophthalmologist, postal code, date of birth, country of birth, occupation (industry), ethnic group, religion, source of referral, diagnoses, and disposal. Data from return visits included the hospital record number, visit date, diagnoses, and disposal. Records for $6 \%$ of the patients $(n=411)$ lacked all demographic data. The first visit for these patients had been recorded as a return visit, and return visit forms lacked the necessary demographic data. These patients were dropped from the study. The number of patients therefore remaining in the study was 6576 .

The variables were categorised as follows. Diagnostic codes followed the International Classification of Diseases, 9th revision." Classification of occupations followed that compiled by the Office of 
Population Censuses and Surveys ${ }^{12}$ with the following additions: housewife, handicapped or disabled, child not in school, schoolchild, and student. The referrals used in this report were general practitioner, selfreferral, general emergency department, and all others. The last category included optician directly, other specialty clinic, community medical officer, and outside referrals such as the Blind Society. Disposals were as follows: return to casualty clinic, admit to eye ward, admit to other ward, day care admission, surgical waiting list, refer to other consultant, blind registration, and discharge. 'Ethnic origins' were designated as Caucasian (Western), Indian/Pakistani, Negro, Oriental, and other. Religions were Christian, Jewish, Hindu, Moslem, Sikh, and other.

The data were first recorded on specially prepared patient visit forms which were filled out by the medical and clerical personnel during each visit. The data were then coded by a technician for input into the computer. The coded data were transferred to magnetic tape at the University of Leicester Computer Laboratory. The data tapes were analysed on the IBM 3081 computer at the Information Technology Service at Stanford University. By means of a program developed within the statistical package, Statistical Analysis System [SAS], the visit records were reorganised into patient records which included a summary of the data from the set of visit records for each patient (Chiapella AP, in preparation).

Out-of-range values in the data for these patients were either corrected or excluded from the statistical analyses. No more than 25 were found for any one

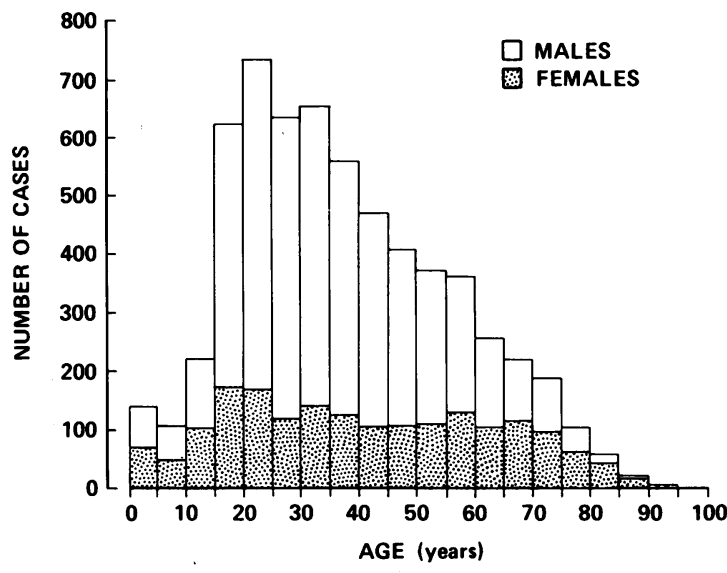

Fig. 1 Age of casualty clinic patients. The age distribution of the patients is subdivided by sex.

variable and most variables had fewer than 10 . The set of patient records was then analysed by procedures provided in SAS.

\section{Results}

\section{DEMOGRAPHIC VARIABLES}

Sex. $29 \%$ of the patients were female and $71 \%$ male.

Age. The median patient age was 23 years. The ages of the patients, subdivided by sex, are shown in Fig. 1.

Country of birth. $85 \%$ of the patients were born in England, $3.5 \%$ in India, $1.5 \%$ in Northern Ireland, $1.4 \%$ in Keyna, $1.3 \%$ in Scotland, $0.9 \%$ in Uganda, $0.9 \%$ in Great Britain (unspecified), $0.5 \%$ in Africa (unspecified), and $<0.5 \%$ from any other country.

Table 1 Most common occupations of patients attending the clinic*

\begin{tabular}{|c|c|c|c|c|c|}
\hline Occupation & Cases & $\begin{array}{l}\text { Median } \\
\text { age }\end{array}$ & $\begin{array}{l}\text { Sext } \\
(F / M)\end{array}$ & $\begin{array}{l}\text { Referralt } \\
\text { (GP/selflother) }\end{array}$ & $\begin{array}{l}\text { Main diagnosis groups } \neq \\
\text { (ker/1//acute conj/2/ } \\
\text { lid inflam/3//injury/4] }\end{array}$ \\
\hline Press, machine toolsetter, operator & 650 & 36 & $1 / 99$ & $12 / 76 / 12$ & $6 / 9 / 3 / 76$ \\
\hline Schoolchild & 412 & 13 & $35 / 65$ & $40 / 45 / 15$ & $6 / 19 / 13 / 50$ \\
\hline Housewife & 304 & 49 & $100 / 0$ & $65 / 29 / 6$ & $12 / 17 / 8 / 17$ \\
\hline Clerk & 222 & 41 & $64 / 36$ & $45 / 44 / 11$ & $8 / 27 / 11 / 29$ \\
\hline Textile worker & 205 & 46 & $61 / 39$ & $45 / 40 / 15$ & $13 / 20 / 7 / 29$ \\
\hline Metal worker, machinist & 189 & 33 & $1 / 99$ & $12 / 71 / 17$ & $4 / 8 / 4 / 77$ \\
\hline Motor vehicle, aircraft mechanic & 190 & 28 & $1 / 99$ & . 9/74/17 & $7 / 9 / 5 / 77$ \\
\hline Construction & 179 & 34 & $1 / 99$ & $15 / 70 / 15$ & $6 / 10 / 6 / 73$ \\
\hline General labourer & 168 & 39 & $2 / 98$ & $15 / 59 / 26$ & $8 / 10 / 4 / 71$ \\
\hline Sheet metal worker & 148 & 29 & $0 / 100$ & $7 / 82 / 11$ & $6 / 10 / 1 / 83$ \\
\hline Electrician & 130 & 32 & $1 / 99$ & $12 / 72 / 16$ & $7 / 9 / 3 / 80$ \\
\hline Distribution manager & 124 & 42 & $12 / 88$ & $23 / 58 / 19$ & $13 / 10 / 7 / 48$ \\
\hline Bus, coach, lorry driver & 123 & 38 & $5 / 95$ & $26 / 62 / 12$ & $7 / 13 / 7 / 72$ \\
\hline Welder & 116 & 38 & $3 / 97$ & $9 / 82 / 9$ & $6 / 5 / 3 / 84$ \\
\hline Student & 110 & 20 & $40 / 60$ & $35 / 52 / 13$ & $10 / 14 / 10 / 38$ \\
\hline Child, not in school & 103 & 2 & $50 / 50$ & $40 / 42 / 18$ & $2 / 35 / 16 / 39$ \\
\hline
\end{tabular}

${ }^{*}$ Includes 100 or more patients. $†$ Percentage of patients.

¥Percentage of patients in this occupation carrying the following diagnoses: [1] Keratitis. [2] Acute conjunctivitis.

[3] Inflammation of the eyelids. [4] Injury. 
Ethnic background. $90 \cdot 3 \%$ were Caucasian (Western), $8 \cdot 0 \%$ Indian or Pakistani, $1 \cdot 3 \%$ black or African, $0.4 \%$ other.

Religion. $83.6 \%$ were Christian, $4.7 \%$ Hindu, $1.8 \%$ Sikh, $1.2 \%$ Moslem, and $8.7 \%$ other or unspecified.

Occupation. Sixteen occupations included 100 or more patients. The median age, sex ratio, source of referral, and main diagnoses for patients in these occupations are summarised in Table 1.

Postal code. Our data, which included patients' postal codes, are compared with catchment population data provided by the LHA. A map of the catchment area of the LHA is provided in Fig. 2. Postal codes LE1-LE5 (mainly the city of Leicester and nearby suburbs) provided $55 \%$ of the patients, LE6-LE9 (suburban areas) provided $32 \%$ of the patients, LE10-LE17 (the most outlying areas of the county) $10 \%$, and the non-LE postal code areas less than $3 \%$ of the patients. The population data show that $41.6 \%$ of the resident population live in LE1LE5, 26.6\% in LE6-LE9 and LE10-LE17, and 5.2\% live in non-LE postal code areas. It is therefore clear that the population in and around the city of Leicester utilises the casualty clinic considerably more than the population from outlying areas.

\section{CLINICAL VARIABLES}

Source of referral. $56 \%$ were self-referred, $30 \%$ were referred by the general practitioner, $8.6 \%$ came from the general emergency department, $1.3 \%$ from other specialty clinic (not LRI), $1.0 \%$ from their optician directly, $0.8 \%$ from the specialty clinic in the LRI, $0 \cdot 2 \%$ were referred by community or school medical officer, and $2 \cdot 1 \%$ came from all other sources.

Number of visits. $79 \%$ of the patients came for one visit to the casualty clinic, $15 \%$ for two visits, and $6 \%$ for more than two visits. Usually after three to four visits the patient was then discharged or referred to the general eye clinic.

Disposal. $78 \%$ were discharged, $32 \%$ were referred to the general eye clinic, $2 \%$ admitted to eye ward, $1 \%$ put on waiting list (for surgery), $0.7 \%$ referred to other consultants, and $0 \cdot 2 \%$ were alloted to all the other disposals. This adds up to over $100 \%$, since some of the patients contributed more than one disposition. Most of these were patients who, after discharge, returned to the casualty clinic and were then referred to the general eye clinic.

Diagnostic categories. The main diagnoses seen at the casualty clinic fell into two general categories: trauma and acute infection/inflammation. As a group, the patients in each of these categories differed from those in the other category with respect to several characteristics. An analysis of these patient groups is presented below.

Trauma was the leading cause of patient presentation to this casualty clinic, accounting for $52 \%$ of the patients attending. The main problems included in this group were corneal abrasion, foreign body on external eye, contusion of eye and adnexa, and burn confined to eye and adnexa. In the age range 5-15 years boys presented with eye trauma twice as often as girls. The patients above age 15 were mainly men,

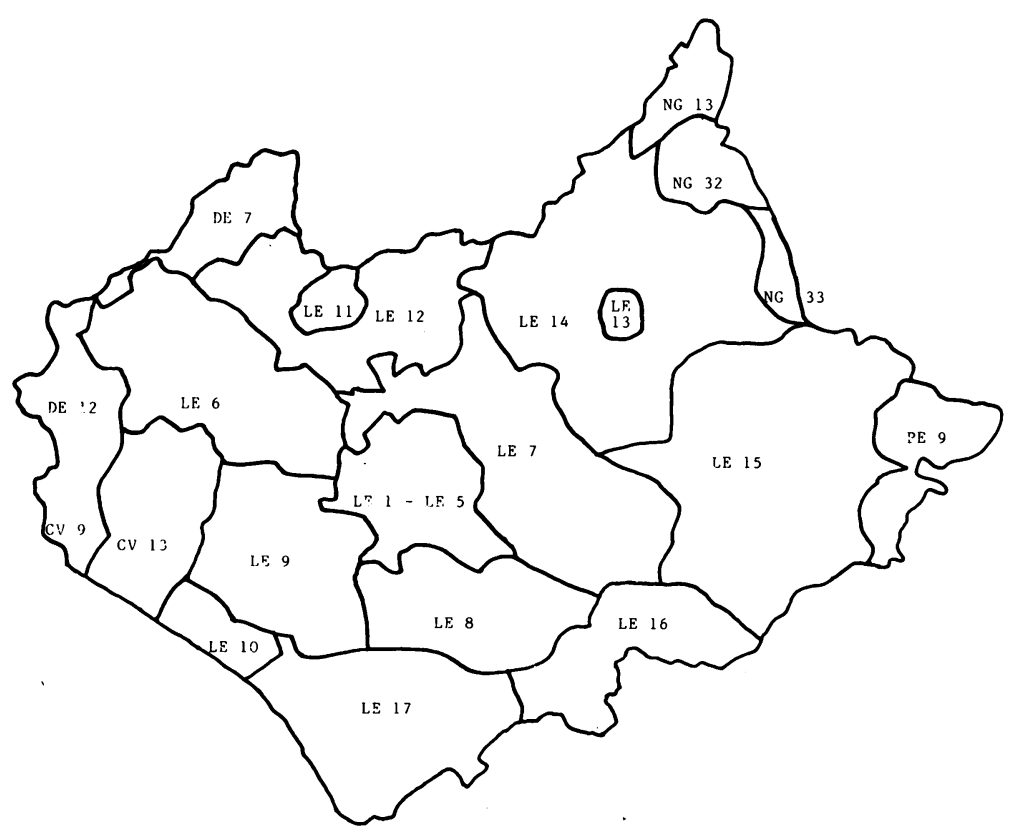

Fig. 2 Map of catchment area of Leicestershire Health Authority showing postal codes. 
and in these patients the injuries were highly influenced by occupation. Over $70 \%$ of the patients with a diagnosis of trauma were self-referred. Table 2 presents a summary of the age, sex, and source of referral for the four most common trauma diagnoses. The majority of the patients with eye trauma came from relatively few occupations. We have identified 11 common occupations in which the risk of eye injury was high. $50 \%$ of the injury cases came from these 11 occupations, while only $35 \%$ of the casualty clinic patients fell into these occupational groups. For patients in these occupations the ratios of accidents to other eye casualty problems was much higher than those found in the remainder of the occupational groups. Table 3 summarises the types of injuries for patients in these 11 occupations.

The second most common diagnostic group into which the eye casualty patients fell was infection/ inflammation, and it accounted for $29 \%$ of the patients attending. The male/female ratio in the various diagnoses included in this group ranged from $0 \cdot 6$ to $2 \cdot 0$. There were many more referrals by general practitioners for this group of patients than for the trauma patients. However, there is considerable variation between diagnoses. Those diagnoses which were mainly general practitioner referrals were keratitis, chalazion, herpes zoster ophthal- micus, and iridocyclitis. Those which were mainly self-referrals were superficial keratitis and conjunctival vascular disorders, for example subconjunctival haemorrhage. Those balanced between self-referral and general practitioner referral were scleritis/episcleritis, corneal ulcer, acute conjunctivitis, deep inflammation of eyelid, entropion and trichiasis of eyelid, blepharitis, and keratoconjunctivitis. A summary of these findings is presented in Table 4.

\section{Discussion}

The main source of emergency ophthalmic care for the population of Leicestershire is the eye casualty clinic located within the general eye clinic of the Leicester Royal Infirmary. This situation provided a unique opportunity to survey eye casualty problems in this diverse population for a one-year period.

On a per capita basis the inhabitants of Leicester utilised the casualty clinic more heavily than people living in outlying areas. There are several possible causes for this finding. (a) Drift to clinics located outside Leicestershire undoubtedly occurs from the outlying areas. (b) General practitioners working at great distances from the LRI may be more likely to treat rather than refer their patients. (c) Fewer prob-

Table 2 Traumapatients

\begin{tabular}{|c|c|c|c|c|}
\hline Injury & Cases & $\begin{array}{l}\text { Median } \\
\text { age }\end{array}$ & $\begin{array}{l}\text { Sex* } \\
(F / M)\end{array}$ & $\begin{array}{l}\text { Source of referral* } \\
\text { (GP/self/gen. casualty } \\
\text { clinic/other) }\end{array}$ \\
\hline Corncal abrasion & 849 & 32 & $22 / 78$ & $12 / 68 / 16 / 4$ \\
\hline Foreign body & 2106 & 32 & $8 / 92$ & $7 / 80 / 9 / 4$ \\
\hline Contusion & 214 & 24 & $23 / 77$ & $19 / 60 / 15 / 6$ \\
\hline Burn & 240 & 27 & $21 / 79$ & $5 / 73 / 12 / 10$ \\
\hline
\end{tabular}

${ }^{*}$ Percentage of patients

Table 3 Occupations presenting with eye injury

\begin{tabular}{|c|c|c|c|c|c|}
\hline \multirow[t]{2}{*}{ Occupation } & \multicolumn{5}{|c|}{ Number of cases } \\
\hline & $\begin{array}{l}\text { All } \\
\text { injuries }\end{array}$ & Burn & Contusion & $\begin{array}{l}\text { Foreign } \\
\text { body }\end{array}$ & $\begin{array}{l}\text { Corneal } \\
\text { abrasion }\end{array}$ \\
\hline Press, machine tool operators & 494 & 13 & 13 & 425 & 64 \\
\hline Motor vehicle, aircraft mechanic & 147 & 10 & 7 & 111 & 18 \\
\hline Metal worker & 145 & 7 & 4 & 111 & 27 \\
\hline Sheet metal worker & 124 & 3 & 3 & 108 & 12 \\
\hline Electrician & 104 & 5 & 3 & 77 & 24 \\
\hline General labourer & 120 & 6 & 5 & 79 & 34 \\
\hline Welder & 97 & 9 & 3 & 72 & 18 \\
\hline Bus, coach, lorry driver & 76 & 4 & 5 & 46 & 23 \\
\hline Others in processing & 51 & 4 & 1 & 23 & 8 \\
\hline Painter and decorator & 44 & 7 & 1 & 23 & 17 \\
\hline
\end{tabular}

Note that the sum of cases in the four injury diagnoses may be more than 'all injury' cases. This is because a few patients had more than one diagnosis. 
Table 4 Acute infection and inflammation: summary of most common diagnoses*

\begin{tabular}{|c|c|c|c|c|}
\hline Diagnosis & Cases & $\begin{array}{l}\text { Median } \\
\text { age }\end{array}$ & $\begin{array}{l}\text { Sext } \\
(F / M)\end{array}$ & $\begin{array}{l}\text { Referralt } \\
\text { (self/GP/other) }\end{array}$ \\
\hline Acute conjunctivitis & 626 & 33 & $44 / 56$ & $38 / 50 / 12$ \\
\hline Chalazion & 246 & 33 & $52 / 48$ & $65 / 28 / 7$ \\
\hline Acute/subacute iridocyclitis & 183 & 49 & $43 / 57$ & $68 / 22 / 10$ \\
\hline Corneal ulcer & 140 & 45 & $33 / 67$ & $53 / 38 / 9$ \\
\hline Scleritis and episcleritis & 122 & 34 & $53 / 47$ & $53 / 36 / 11$ \\
\hline Conjunctival vascular disorders & 115 & 46 & $39 / 61$ & $24 / 61 / 15$ \\
\hline Superficial keratitis without conjunctivitis & 100 & 30 & $38 / 62$ & $31 / 55 / 14$ \\
\hline Hordeolum and other deep inflammation of eyelid & 82 & 30 & $43 / 57$ & $46 / 41 / 13$ \\
\hline Herpes zoster with ophthalmic complications & 73 & 67 & $55 / 45$ & $85 / 13 / 2$ \\
\hline Interstitial and deep keratitis & 65 & 47 & $42 / 58$ & $56 / 26 / 18$ \\
\hline Other and unspecified keratoconjunctivitis & 66 & 55 & $61 / 39$ & $60 / 26 / 14$ \\
\hline Entropion and trichiasis of cyclid & 60 & 45 & $44 / 56$ & $44 / 45 / 11$ \\
\hline Blepharitis & 57 & 39 & $52 / 48$ & $50 / 43 / 7$ \\
\hline
\end{tabular}

*Cases with trauma have been deleted from this Table.

†Percentage of patients.

lems, especially injury, may occur in rural areas. (d) The different distribution of occupations between city and rural areas may account for these differences. (e) Finally, attitudes held by people in these areas may lead to differences in utilisation of medical resources. Patients in rural areas may not wish to come into Leicester because of the inconvenience, loss of earning, difficulty in transport, and also because they may have a much higher threshold before they seek professional medical help.

A typical patient coming to the eye casualty clinic during the study year was a man of working age with an eye injury. He was self-referred and came for one visit only. He was likely to be in one of several occupations which appeared to be at risk for eye injury. Although data are not available on the incidence of injury at work versus that outside work, it seems reasonable to assume that most of the injuries occurred at work, since the patients presented to the eye casualty clinic during normal working hours. This presumed high rate of jobrelated injuries would indicate that these workers are not being adequately protected by eye shielding devices. This could be due to inadequate devices, a lack in supplying of devices, and/or the improper use of devices when provided. The second possibility is that these workers, when not at work, sustain injuries more often than others. They may involve themselves in more risky activities, such as sports or motor car and house repair. Identifying the specific causes of the high rate of injuries deserves further attention.

In this study boys presented with eye injury twice as often as girls. This finding is in the same direction as those presented by other investigators for injuries in children. ${ }^{5-8}$ The ratio, 2:1, is lower than that noted by other authors, who have reported ratios of $3: 1$ and higher. ${ }^{5-8}$ In contrast to the other studies the patients in our study were not admitted to hospital. This may indicate that the ratio of eye injury in boys versus girls may be smaller for less severe injury than for those injuries requiring admission to hospital.

Although this study has concentrated mainly on summarising data on the patients attending the eye casualty clinic over a one-year period, it has raised the possibility of providing further epidemiological information, especially with regard to occupations at risk for specific ocular injury and the possibility of seasonal variation in emergency ophthalmological disease.

The collection of data is continuing, analysis of which should throw better light on utilisation of ophthalmic emergency facilities by this population.

The authors thank the consultants, junior staff, and clerical staff of the Eye Clinic of the Leicester Royal Infirmary for their participation and co-operation during this study. Particular appreciation is given to Marcus Lesniak for his enormous contributions. Also thanks to Dr J Jones, who provided the population statistics of the Leicestershire Health Authority.

The work was supported in part by National Research Award EY 07035 and by an unrestricted research grant from Research to Prevent Blindness.

\section{References}

1 Canavan YM, O'Flaherty MJ, Archer DB, Elwood JH. A 10year survey of eye injuries in Northern Ireland, 1967-76. $\mathrm{Br} \mathrm{J}$ Ophthalmol 1980; 64: 618-25.

2 Chapman-Smith JS. Eye injuries: a twelve-month survey. $N Z$ Med J 1979; 90: 47-9.

3 Garrow A. A statistical enquiry into 1000 cases of eye injuries. BrJ Ophthalmol 1923; 7: 65-80.

4 Ilsar M, Chirambo M, Belkin M. Ocular injuries in Malawi. Br J Ophthalmol 1982; 66: 145-8.

5 Maltzman BA, Pruzon H, Mund ML. A survey of ocular trauma. Surv Ophthalmol 1976; 21 : 285-90.

6 Grignolo FM, Biovenale R, Lorenzi U, Lombardo L. Epidemiology of eye injuries in children under 16 ycars of age. Minerva Pediatr 1983; 35: 747-52.

7 Lambah P. Some common causes of eye injury in the young Lancet 1962; ii: 1351-3. 
8 Niiranes M, Raivio I. Eye injuries in children. Br J Ophthalmol $1981 ; 65: 436-8$.

9 Hay SH. Ocular presentations in the emergency department. J Med Assoc State Ala 1977; 47: 23-4.

10 Olesen JM. Eye problems in an emergency department. Ugeskr Laeger 1983; 145: 2051-3.
11 World Health Organisation. International classification of diseases, revision. Ann Arbor: Commission of Professional and Hospital Activities, 1980.

12 Office of Population Censuses and Surveys. Classification of occupations. London: Her Majesty's Stationery Office, 1980 